\title{
ATUAÇÃO DO PESSOAL DE ENFERMAGEM NAS MEDIDAS DE CONTROLE DE INFECÇÕES HOSPITALARES
}

\author{
Celina da Cunha Tibiriçá *
}

\section{INTRODUÇAOO}

O presente trabalho foi baseado em observações e entrevistas dirigidas a enfermeiros, pessoal dos Serviços de Lavandaria, Limpeza, Nutrição e Dietética, Pessoal, Farmácia, Arquivo Médico e Estatística e membros de Comissão de Infecção de dezesseis (16) hospitais dos quarenta e um (41) existentes em Porto Alegre. Das 64 pessoas entrevistadas $\mathbf{7 3 , 4 3 \%}$ eram enfermeiras.

\section{INFECÇÃO HOSPITALAR}

Infecção Hospitalar é aquela adquirida no hospital, mesmo quando manifestada após a alta do paciente. Alguns autores são mais exigentes, incluindo também aquela que não tenha sido diagnosticada na admissão do paciente, por motivos vários, como prolongado período de incubação ou ainda por dificuldade diagnóstica.

O Serviço de Enfermagem representa um papel relevante no controle de infecções por ser o que mais contatos mantém com os pacientes e por representar mais de $50 \%$ do pessoal hospitalar. Colaboram também com destaque, na redução de infecções hospitalares, os Serviços Médicos, de Limpeza, Nutrição e Dietética, Lavandaria e de Auxiliares de Diagnóstico e Tratamento. $O$ apoio da Administração. Superior do Hospital e a colaboração dos demais servidores, em toda a escala hierárquica, desde o Administrador até o Servente, fazem-se indispensáveis.

Afora o esforço permanente e sistematizado de todo o pessoal hospitalar, muito do bom êxito na execução de medidas de preven-

* Coordenadora do Depto. de Enfermagem Winthrop. 
ção e controle de infecções vai depender da planta física, equipamentos, instalações e da capacidade do pessoal.

\section{INCIDÊNCIA DE INFECÇס̃ES}

Independente do bom atendimento dos pacientes, a adoção de medidas preventivas contra as infecções é dificultada pelas deficiências encontradas na planta física de nossos hospitais, tais como a localização dos ambulatórios, o controle do acesso de pacientes externos ao Centro Obstétrico, Centro Cirúrgico, Berçário, Lactário, Unidade de Queimados, etc. O número deficiente de elevadores obriga a permissão do transporte promíscuo de pacientes, de carros térmicos de alimentação, de roupa limpa e suja, de visitantes e de pessoal hospitalar. Dependências físicas com áreas deficientes dificultam a execução de técnicas médicas e de enfermagem, assim como as grandes enfermarias onde a superlotação concorre para o aumento de infecções cruzadas. A falta de quartos individuais, com sanitários próprios em cada unidade de internação, não facilita a montagem de isolamento para pacientes portadores de doenças infecto-contagiosas e para os suspeitos. A simples, enfatizada e indispensável lavagem constante das mãos do pessoal hospitalar, na prevenção de infecções, afigura-se, às vezes, de difícil adoção pelo número reduzido de lavatórios e pelo seu tipo inadequado. A localização inconveniente de certos setores que devem ser próximos entre si, como o Centro Obstétrico e Berçário à Unidade de Internação Obstétrica, as Salas de Operações à Unidade de Recuperação Pós-Anestésica e esta à Unidade de Tratamento Intensivo. como as construções de material de má qualidade, permitindo a infiltração de água e a falta de incineradores de lixo, são critérios muitas vezes não observados pelos responsáveis pelas construções de nossos hospitais.

Outros fatores contribuem para um maior índice de infeç̧ăo, seja pela maior exposição dos pacientes aos germes ,seja pela alteração de suas resistências naturais: longa permanência no hospital, grandes cirurgias, anestesia prolongada, deambulação precoce, o emprego mais freqüente de transfusões de sangue, o emprego de medicamentos que afetam a resposta imunológica, tratamentos relaxantes musculares e hipotérmicos.

Qual é o índice de infecção de nossos hospitais?

Pouquíssimos hospitais estão em condições de informar seu índice de infecção já que não existe obrigatoriedade, por parte dos medicos ou de outros profissionais da equipe de saúde, de notificação, a um órgão central, das infecções diagnosticadas na admissão 
e durante a permonência dos pacientes no hospital. No nosso caso 93,75 dos hospitais não informaram seu índice de infecção.

O grupo responsável pelo controle de infecções do hospital deve elaborar os critérios pelos quais os membros da equipe de saúde concluirão pela necessidade de isolamento do paciente, já que é um assunto controvertido. A elaboração do relatório diário do índice de infecção o que pode ficar sob a responsabilidade do médico ou da enfermeira do paciente. O registro das infecções hospitalares é importantíssimo para o estudo das fontes de infecção.

Compreende-se que a infecção hospitalar seja indesejável por todos os responsáveis por um bom padrão de atendimento aos pacientes internados; o que não se compreende é que os casos de infecção hospitalar sejam ignorados ou mesmo negados por temor que estes fatos, dados a conhecer, desprestigiem o hospital. Tais atitudes impedem que se executem medidas de isolamento, de limpeza concorrente e desinfecção terminal, de modo a evitar a propagação de infecção, mesmo dispondo de instalações adequadas, material necessário e de pessoal capacitado para o combate à infecção.

\section{CAUSAS DE INFECÇÃO HOSPITALAR}

\section{Uso inadequado de antibióticos}

Na literatura consultada encontra-se como uma das causas de aumento de incidência de infecção o uso indiscriminado de antibióticos que fizeram surgir raças resistentes a esses agentes antimicrobianos entre os germes sensíveis.

\section{Manipulação diagnóstica}

A atuação do pessoal de enfermagem nas medidas diagnósticas tais como cateterismo cardíaco, arteriografias, biópsias por punção, aspiração de líquidos (cerebral, pleural, peritonial, sinovial), etc. quando deixa de atender os princípios de esterilização, pode oferecer risco de contaminação e posterior infecção.

\section{Pessoal}

Sabe-se que o elemento humano é a principal fonte de infecção no hospital e um "check-up" da saúde individual do pessoal hospitalar, na sua admissão, é uma medida adotada pelos nossos hospitais, embora ainda não tenham estabelecido a freqüência e os tipos de exames clínicos, laboratoriais, imunizações, segundo uma escala de prioridade e de acordo com as atividades exercidas pelo pessoal, nos mais diferentes setores do hospital. Assim, para o pes- 
soal que trabalha em áreas críticas como Berçário, Lactário, Centro Cirúrgico, Centro Obstétrico, Unidade de Tratamento Intensivo, Unidade de Recuperação Pós-Anestésica, Pediatria, Lavandaria, Serviço de Nutrição e Dietética e Radiologia, os exames devem ser mais minuciosos e os prazos menores.

Houve unanimidade nos 16 hospitais quanto à exigência do exame clínico, abreugrafia e imunizações anti-variólica e anti-tífica, para a admissão de pessoal hospitalar.

Cada hospital deve estabelecer as prioridades e a freqüência dos exames que julgar necessários ao controle sanitário do seu pessoal hospitalar, levando em consideração também as fontes de infecção identificadas e as possibilidades dos recursos materiais e humanos do Serviço de Análises Clínicas. Essa medida visa à proteção do pessoal e dos pacientes pelo afastamento do trabalho dos portadores de infecções, aparentes ou não. O controle sanitário de todo o pessoal hospitalar, após a admissão, está por receber de nossos hospitais a atenção que merece. Apenas $18,75 \%$ dos hospitais se mostram interessados em manter uma vigilância epidemiológica de seu pessoal, o que é de se lamentar.

\section{Pacientes, familiares $e$ visitantes}

A prevenção de propagação de infecções decorrentes dos pacientes, familiares e visitantes repousa na educação sanitária destes. A supressão do simples aperto de mãos entre pacientes, familiares e visitantes, o sentar na cama dos pacientes, o trânsito por outras áreas do hospital, as visitas entre os pacientes e a redução do número e a proibição de visitas de crianças menores de 12 anos e de pessoas convalescentes, são algumas das recomendações que, por certo, concorrerão para a prevenção de infecções no ambiente hospitalar. Os pacientes devem ser também orientados quanto às medidas de higiene e proteção que devem tomar, em relação ao contágio da doença de que é portador.

\section{Atos cirúrgicos}

É comum atribuírem o aparecimento de infecção pós-operatória a falhas na esterilização do material cirúrgico que, embora seja um fator crítico, não é o único responsável pelas infecções em cirurgias. Há necessidades de se investigar em qual tempo operatório a infecção se originou, isto é, no trans-operatório, por falhas no Centro Cirúrgico ou no pré e pós-operatório, por falhas nas medidas de diagnóstico, de tratameento médico e nos cuidados de enfermagem executados nas unidades de internação. 
As infecções no trans-operatório podem decorrer de vários fatores: falhas nas técnicas de esterilização de instrumental cirúrgico, roupas, outros materiais e utensílios em geral; mau funcionamento dos aparelhos de esterilização; a manipulação incorreta do material estéril; a antissepsia deficiente das mãos e antebraços da equipe cirúrgica; o desconhecimento ou a displicência na conduta e na indumentária preconizada a toda a equipe envolvida no ato cirúrgico; dependências do Centro Cirúrgico fora dos padrões recomendáveis e a não observancia de outras normas que impeçam a contaminação dos pacientes e do ambiente.

A avaliação bacteriológica do instrumental cirúrgico, de outros materiais e do ambiente hospitalar deve merecer mais interesse por parte do pessoal de enfermagem que, com a colaboração do Serviço de Análises Clínicas ou da Comissão de Infecção, deve fazer-se representar para o estabelecimento dos métodos de controle bacteriológico e sua freqüência.

Não é demasiado insistir na necessidade de um maior interesse científico na avaliação bacteriológica freqüente dos veículos e fômites no meio hospitalar.

\section{Tratamento}

Constituem poderosas armas no combate às infecções decorrentes de falhas nas unidades de internação e demais áreas do hospital, o ensino e a supervisão do pessoal que trabalha no hospital, para adoção de medidas preventivas e para execução de técnicas de combate à infecção hospitalar.

Através da leitura da anamnese completa, por ocasião da admissão e da interpretação dos resultados dos exames complementares e baseados nos critérios de infecção estabelecidos, o pessoal de enfermagem pode constantar pacientes infectados, a fim de se tomarem as medidas de isolamento, estas medidas, aliadas à higienização completa dos pacientes na admissão, durante sua hospitalização e principalmente antes de serem levados à cirurgia e a limpeza de sua unidade, se constituem em importantes medidas na redução de infecções decorrentes dos pacientes, nas unidades de internação.

O isolamento do paciente infectado embora não deva ser negligenciado o que se vê na maioria das vezes, em relação ao isolamento de pacientes em unidades de internação comuns, são medidas que se resumem na transferência do paciente para um quarto individual e na colocação do avental sobre a roupa daqueles que vão entrar em contato com o paciente. 
A orientação do pessoal hospitalar, no desempenho de técnicas de limpeza, de desinfecção e de assepsia deve ser contínua, formal e informal.

Precisa ser intensificado o desenvolvimento de programas de atualização no que concerne à prevenção, combate e controle de infecções hospitalares extensivos a todo o pessoal hospitalar, principalmente àqueles que mantêm contatos com os pacientes e os seus fômites. O Serviço de Enfermagem se preocupa em 33,33\% com a atualização dos conhecimentos de seu pessoal no desempenho de suas atribuições, porém, necessita dar continuidade e realce aos conteúdos programáticos relacionados com a prevenção de infecções e atenção de enfermagem aos pacientes infectados.

A maioria das infecções hospitalares é transmitida pelo contágio direto, através de mãos contaminadas. A lavagem das mãos antes e depois de cuidar de cada paciente e às vezes no decurso de diversos tratamentos prestados ao mesmo paciente com emulsão detergente bacteriostática e enxutas com ar quente ou com toalhas de papel se constitui em método eficiente para evitar a propagação de germes. As bactérias transientes das mãos são facilmente eliminadas com o uso de antissépticos adequados o que não acontece com o uso do sabão comum que exige uma lavagem de 5 a $10 \mathrm{mi}-$ nutos para eliminar os microorganismos presentes.

Y. Hara,(3) realizou uma pesquisa no hospital de Clínicas da FMUSP para comprovar a contaminação das mãos e a presença de germes patogênicos antes e após a arrumação de camas de pacientes ambulantes e acamados; além de germes saprófitas constatou a presença de Estafilococo Dourado mesmo na arrumação de camas de pacientes ambulantes, onde a contaminação foi menor do que na cama de pacientes acamados.

Por desempenhar um papel importante na disseminação de doenças, U. Zanon(13) aconselha que "as mãos do pessoal de unidades de internação sejam testadas uma vez por mês e as mãos dos responsáveis pelo preparo das mamadeiras uma vez por semana.

No Lactário, as mamadeiras e os bicos devem ser testados diariamente, inclusive o conteúdo da mamadeira logo após o seu preparo e 24 horas após a estocagem, a fim de detectar possíveis contaminações. A água de beber deve ser fervida e examinada uma vez por semana, assim como a água dos umidificadores de oxigênio e a das incubadoras.

Em estudo comparativo realizado por M. I. Teixeira (10) sobre as condições bacteriológicas do Berçário, Centro Cirúrgico e Sala de Parto, durante três meses, num hospital do Rio de Janeiro e constatou 490 colônias no Berçário, 233 no Centro Cirúrgico e 191 na Sala de Parto. No que se relaciona com os germes isolados em cada 
dependência, a situação foi desfavorável ao Berçário onde foram identificadas 26 amostras de Estafilococos patogênicos (coagulase positiva), enquanto no Centro Cirúrgico foram encontradas 8 e na Sala de Parto 4.

Dentre os setores do hospital sobresai-se o Berçário em face da alta mortalidade do recém-nascido, por causa de sua suscetibilidade.

$\dot{E}$ insistentemente destacada na literatura a importância da lavagem freqüente das mãos com antissépticos adequados e a necessidade de comprovação científica da eficiência das rotinas e procedimentos médicos e de enfermagem sob as nossas condições ambientais, humanas e materiais.

Os Serviços de Limpeza e Lavandaria são responsảveis por atividades importantes na redução de infecções pela remoção do pó e a correta desinfecção das roupas, atividades que devem ser coordenadas por pessoas com suficiente preparo básico. Não se estaria exigindo demasiado se o Coordenador do Serviço de Limpeza possuísse instrução equivalente ao $1 .^{\circ}$ grau completo; conhecimentos científicos relacionados à higiene, à limpeza e à desinfecção; interesse em progredir na sua área de trabalho e habilidade para treinar e supervisionar o seu pessoal. As exigências para o cargo de Coordenador do Serviço de Lavandaria devem ser também maiores, pela importância de suas atividades na segurança e bem-estar dos pacientes.

\section{COMISSÃO DE INFECÇÃO}

Apenas $37,50 \%$ de nossos hospitais possuem uma Comissão de Infecção ou um pessoa com atribuições definidas para o controle de infecções que, além de outras responsabilidade tão bem enumeradas por C. G. Melo,(4) é o órgão responsável pela indicação dos diversos produtos químicos utilizados no hospital. Muitos de nossos hospitais $(68,75 \%)$ deixam a critério do Serviço de Enfermagem a indicação dos antissépticos e desinfetantes e, para esta responsasabilidade complexa, deve preparar-se para estar em condições de estabelecer os critérios técnicos para a escolha dos mesmos, realizar ou colaborar nos testes bacteriológicos e na avaliação dos produtos químicos que indica para os diversos fins no hospital.

Segundo U. Zanon(14) os critérios técnicos para a escolha de germicidas hospitalares são: o registro no Serviço Nacional de Fiscalização de Medicina e Farmácia, o estudo da composição química e sua adequação às finalidades do produto e a comprovação bacteriológica da atividade germicida.

O pessoal de enfermagem deve usar os desinfetantes e antissépticos baseado em resultados de sua própria experiência, tendo em 
vista os germes responsáveis pelas infecções no hospital onde trabalha.

A criação de Comissão de Infecção é justificada e recomendada, e deve constituir-se em órgão coordenador de atividades de investigação, prevenção e controle de infecções.

A constituição de uma Comissão de Infecção pode variar segundo o tamanho do hospital, não deixando, porém, de ter um representante do Serviço de Enfermagem, em tempo integral, para atuar como um dos membros executivos das normas baixadas pela Comissão.

Reduzir infecções no hospital é um trabalho gigantesco que exige a colaboração contínua e eficiente de todo o pessoal hospitalar

\section{RECOMENDAÇÕES}

Considerando a importância que tem a redução de infecções nos hospitais para a diminuição do risco de morbidade e mortalidade, do custo do tratamento e da média de permanência dos pacientes nos hospitais que resulta numa maior utilização de leitos hospitalares, recomenda-se que os:

\section{I - Administradores de Hospital:}

- Possibilitem aos Serviços do Hospital condições materiais e humanas para a montagem de isolamento de pacientes infectados e suspeitos e para a adoção das demais medidas preventivas e de controle de infecções;

- se assessorarem de pessoal capacitado nas construções e reformas de hospitais a fim de que a planta física não venha a dificultar a adoção das medidas de redução de infecções;

- tornem compulsória, por parte dos profissionais da equipe da saúde, a notificação a um órgão central das infecções hospitalares e não hospitalares;

- mantenham um serviço de vigilância sanitária para o pessoal hospitalar;

- ofereçam ao grupo ou à pessoa responsável pelo controle de infecções os Serviços de Análises Clínicas para a identificação dos agentes etiológicos;

- incentivem a realização de cursos de atualização de conhecimentos no que concerne a prevenção e controle de infecções para todo o pesscal que mantenha contatos diretos e indiretos com os pacientes;

- estimulem os serviços Médicos, de Enfermagem, Nutrição e Dietética, Lavandaria, Limpeza e Auxiliares de Diagnóstico e Tra- 
tamento a elaborarem normas para o seu pessoal referentes à prevenção e controle de infecções;

- estabeleçam critérios mais exigentes para a indicação dos responsáveis pelos Serviços de Limpeza e de Lavandaria de modo a se ter pessoal mais qualificado para o desempenho de atividades que muito concorrem para a redução de infecções;

- criem a Comissão de Infecção ou designem uma pessoa com atribuições definidas para reduzir ao mínimo as infecções hospitalares;

- permitam a compra de antissépticos e desinfectantes utilizados para os diversos fins no hospital quando justificada por critérios técnicos.

\section{II - Serviços de Enfermagem:}

- Valorizem e realizem, sistematicamente, avaliação bacteriológicas da desinfecção e esterilização do material hospitalar assessorados por técnicos no assunto;

- supervisionem o seu pessoal na desinfecção e esterilização de material e do ambiente, no tratamento e no processo de atenção de enfermagem ao paciente infectado;

- desenvolvam cursos para o seu pessoal dando realce aos conteúdos relacionados com a atenção de enfermagem a pacientes infectados e à prevenção de infecções;

- se façam representar na Comissão de Infeç̧ão designando uma enfermeira, em tempo integral, como coordenadora da execução de sua parte no programa de controle de infecções no hospital;

- procurem ampliar seus conhecimentos sobre antissépticos e desinfetantes muito especialmente quando se responsabilizar pela indicação dos mesmos para os diversos fins no hospital.

\section{REFERENCIAS BIBLIOGRAFICAS}

1 - AGUIAR, Nildo - Infecções Hospitalares. Importância Médica, Sanitária e Administrativa. Conferência proferida no Centro de Estudos do Hospital de Ipanema, 1971.

2 - DELGADO, Margareta Luce - Princípios básicos de enfermagem no controle da Infeç̧ão Hospitalar. In: Zanon Uriel, - Epidemiologia e Profilaxia da Infecção Hospitalar. Guanabara, Valmont Winthrop.

3 - HARA, Yoriko - Contaminação das mãos na arrumação de cama. Revista Brasileira de Enfermagem, 19 (5 e 6): 524-534, outubro-dezembro, 1966.

4 - MELLO, Carlos Gentile - A coordenação das medidas preventivas contra as infecções hospitalares. Revista Paulista de Hospitais, 20 (9): 18-23, setembro, 1972. 
5 - NEVES, Ana Piuma - Fontes de contaminação da ferida cirúrgica. Apostila Escola de Enfermagem da UFRGS.

6 - PESSOA, Alba Lins - Fontes de infecção no hospital. Revista Paulista de Hospitais, 20 (8): 30-33, agosto, 1972.

7 - PIERINI, Maria Aparecida - Contribuição da enfermeira no controle da contaminação hospitalar. Revista Brasileira de Enfermagem, 24 (6): 174-202, outubro-dezembro, 1971.

8 - ROCHA, Semiramis Melani Melo e Castro, José Roberto - Prevenção de infecções no berçário através da organização de um lactário. Revista Paulista de Hospitais, 21 (10): 448-450, outubro, 1973.

9 - SILVA, Newton Neves - Infecções Hospitalares Apostila UFRGS.

10 - TEIXEIRA, Manuel Isnard Souza - Estudo das condições bacteriológicas de um hospital. Revista Brasileira de Enfermagem, 12 (1, 2 e 3): 83-91, janeiro-junho, 1969.

11 - ULIANA, Aida - Serviço de Limpeza num hospital geral de 500 leitos. Revista Paulista de Hospitais, 17 (8): 14-22, agosto, 1969.

12 - WILliAMS, Christopher P.S. e Oliver, Thomas K. - Rotinas de Berçário e colonização estafilocócica do recém-nato. O Semestre Tepêutico, 12 (28): 13-21, dezembro, 1973.

13 - ZANON, Uriel - Controle bacteriológico das infecções hospitalares. In: Zanon Uriel - Epidemiologia e Profilaxia da Infecção Hospitalar. Guanabara, Valmont Winthrop.

14 - ZANON, Uriel - Desinfetantes, antissépticos e infecção hospitalar. O Semestre Terapêutico, 12 (28) : 48-64, dezembro, 1973.

15 - ZANON, Uriel - Fundamentos para o controle das infecções adquiridas em hospital. O Semestre Terapêutico, 12 (28): 2-12, dezembro, 1973. 